\title{
Malignant melanoma in Rome, Italy, 1970-9
}

\author{
G PETRELLI, ${ }^{1}$ M MAGGINI ${ }^{1}{ }^{\text {F }}$ TAGGI ${ }^{1}$ AND G MORPURGO² \\ From the Department of Epidemiology and Biostatistics, ${ }^{1}$ Istituto Superiore di Sanità, Viale Regina Elena, 299, \\ Rome, 00161 and 'University of Rome "La Sapienza", Rome, Italy
}

SUMMARY An epidemiological study was conducted in the city of Rome and the incidence of malignant melanoma was determined retrospectively for the years 1970-9. All patients had legal residence in Rome and a histological diagnosis of melanoma during that period; only cases of malignant melanoma of the skin (ICD 172, 8th revision) were considered. A total of 17 public and 82 private hospitals were involved in the study with 11081 and 6127 hospital beds respectively. All the hospitals in the study had one of the following therapeutic and diagnostic facilities: internal medicine, dermatology, oncology, radiology, surgery, plastic surgery, histopathology. Analyses of incidence are based on 500 cases, 237 males and 263 females, collected in the period 1970-9. The data indicate a positive time trend in incidence; the average annual increase is 0.27 cases/year per 100 000. The data show that in a Mediterranean and Latin country such as Italy the incidence of melanoma presents the same ascending trend as that of other Caucasian countries, whether European or not, the slope of the curves is similar for both sexes. The distribution of the primary site for both sexes is closely parallel to that described for all Caucasian populations, the lower limbs being more affected in females and the trunk in males.

The problem of the aetiology of cutaneous malignant melanoma and its rapidly increasing incidence and mortality rate in all western countries has caused considerable concern. ${ }^{12}$

A number of studies have dealt with factors tentatively associated with the aetiology of melanoma; ${ }^{3-5}$ extensive discussions on the role of exposure to sun as a risk factor have been reported. ${ }^{6-9}$

The relation between the incidence of melanoma and latitude has been widely analysed. A negative correlation with latitude in North America and a positive one within Europe has been found. ${ }^{10} 11$

It should be pointed out also that within some European countries such as Norway ${ }^{12}$ and England and Wales ${ }^{13}$ the incidence of melanoma increases from north to south, as it does in North America. This suggests that in a relatively homogeneous population, such as the whites of North America or the population of a single European country, the incidence of melanoma increases with decreasing latitude, possibly because of increasing exposure to sun, whereas in the European population as a whole, racial factors outweigh the differences attributable to latitude. Latin populations are generally considered less likely to develop malignant melanoma; it is therefore particularly interesting to see whether Latin countries, disregarding the absolute incidence, display the same ascending trend as the northern countries of Europe.

In Italy, a threefold increase in mortality from melanoma has been observed in the last two decades. ${ }^{14}$ The average mortality rate per year was 0.3 per 100000 inhabitants in the period 1955-7, while in the years $1976-8$ it rose to 0.9 per 100000 (age standardised rates). A cohort effect has also been shown, suggesting that successive cohorts have experienced an increased risk of developing melanoma. The trend in incidence of melanoma in Italy has not been analysed until now , as there was never an operating Cancer Registry. In 1974 the Lombardy Cancer Registry was established; the registration area covers one province (the Varese province with 777626 inhabitants in 1977) in northern Italy. At present cancer incidence and mortality rates for the years 1976-7 are available.

In this paper we report the results of an epidemiological study conducted in Rome. The incidence of malignant melanoma in Rome and its 
time trend in the period $1970-9$ are reported; incidence by age, sex, and anatomical site is analysed as well.

\section{Materials and methods}

Rome lies in the centre of Italy and is the largest city in the country; according to the census of 1971 it has 2781993 inhabitants.

The municipal health service comprises 124 private and 29 public hospitals, including two university teaching hospitals, two dermatological hospitals, and a cancer hospital. There are a total of 27091 hospital beds, $64 \%$ of which are in public hospitals with an average of 595 beds in each; $36 \%$ are in private hospitals with an average of 79 beds in each.

Only public or private hospitals with one of the following therapeutic and diagnostic facilities were involved in the study: internal medicine, dermatology, oncology, radiology, surgery, plastic surgery, histopathology.

In order to study the incidence of malignant melanoma in Rome, a retrospective study was planned to find all cases of melanoma diagnosed during the period 1970-9. All the cases were patients who had legal residence in Rome and a histological diagnosis of melanoma during that period; the cases were all malignant melanoma of the skin (ICD 172, 8 th revision). Cases with multiple registrations were considered only once according to the first histological diagnosis of melanoma; metastatic tumours with a diagnosis of primary melanoma made before 1970 were not considered.

A total of 17 public and 82 private hospitals were involved in the study with 11081 and 6127 hospital beds respectively.

In the public hospitals we examined the records ourselves to identify patients with a diagnosis of melanoma. A standard form was completed on each identified patient. The following information was sought: name and surname, sex, date and place of birth, marital status, occupation, residence, date of first diagnosis of melanoma, site of the tumour, and past history of disease.

A postal survey was conducted for the private hospitals (as outlined in the Appendix) to ascertain the number of cases of melanoma diagnosed in the period 1970-9. Out of 82 private hospitals that received the questionnaire, $66(80 \%)$ completed and returned it. Among the respondents, 19 cases of melanoma have been collected. For each case the standard form, cited above, was completed.

In order to estimate biases due to the procedure used in the private hospitals, a sample (14 private hospitals), including both respondents and non-respondents, was examined by us with the same method that was used for the public hospitals. The sample was not a random one owing to the difficulty of obtaining the permission of the chiefs of the private hospitals to review their clinical records. The private hospitals checked were, however, similar to other private hospitals both for the number of hospital beds and for the therapeutic and diagnostic facilities. In this way 23 further cases of melanoma (Rome residents) not claimed in the questionnaire were found.

The resulting ratio is 1.8 cases per 100 hospital beds; therefore we can roughly estimate that 108 cases might have been present in all the private hospitals during the decade, 66 more cases than those found. These estimated cases are not considered in the present analysis.

A rough estimate of the number of melanoma patients, resident in Rome but diagnosed elsewhere, has been made by checking the hospital cancer registry of Milan National Cancer Institute, where the WHO Collaborating Centre for Evaluation of Diagnosis and Treatment of Melanoma is located. This centre is the only one specialised in melanom diagnosis and treatment in Italy. Only seven case $\bar{D}$ were found to have been first diagnosed in the Milarti Cancer Institute during the decade. This confirms that a Rome resident's first diagnosis of melanoma is rarely made outside Rome.

Fifty-four cases with a diagnosis of melanoma were found for which no further data were available. These cases were not considered in the analysis.

The cases have been classified as follows according to the primary site of malignant melanoma: head-neck, trunk, upper limb (including hand and palm), and lower limb (including foot and sole). There were 33 patients for whom the primary tumour site was never recorded; these have been excluded from the analysis of incidence of melanoma by anatomical site.

Histopathological reports of melanoma were not standardised in Rome hospitals, so analysis of incidence according to the histopathological features of the lesion has not been undertaken.

Age-sex adjusted incidence rates are reported Direct adjustment has been made using the Rome population of 1971 (census year) as a standard.

\section{Results and discussion}

\section{INCIDENCE TREND}

Analyses of incidence presented in this study are based on 500 cases, 237 males and 263 females, effectively collected in the period 1970-9. We consider this as a minimum estimate due to the possible biases discussed above. This 
underestimation, however, is unlikely to affect the time trend of the disease as no clustering of the cases not claimed by private hospitals has been found within the 10 years of the study. Moreover the 54 cases not considered because complete data were not available were uniformly distributed over the 10 years; the time trend of melanoma results was not altered even considering these cases all as legal residents of Rome.

Age adjusted incidence rates of melanoma by year and sex and the absolute number of cases are given in the table. In order to avoid possible bias due to improved diagnosis in older age groups in more recent years, truncated incidence rates have been calculated. As melanoma is extremely rare in childhood and early adult life, the data have been restricted to the age range $20-60$ years. Truncated incidence trend does not show striking differences from the trend for all ages, making us confident of the accuracy of the rates.

In figure 1 the time trend in incidence of disease for both sexes is shown for the period 1970-9 indicating a rather constant increase in incidence; the average annual increase is $\mathbf{0 . 2 7}$ cases/year per 100000 .

\section{AGE AND SEX}

Because of the small number of cases, age-specific incidences and rates by anatomical site are averaged over two successive five-year periods (1970-4 and 1975-9) to provide more stable rates.

Age-specific incidence rates of melanoma according to sex are shown in figure 2 . An increasing incidence trend is evident for both sexes and all age groups after age 20 . Below this age only 10 cases have been found in Rome in the 10 years studied. The curves of the age specific rates are quite similar in the first period (1970-4) in females and males, while contrast by sex is observed in 1975-9. The curve for

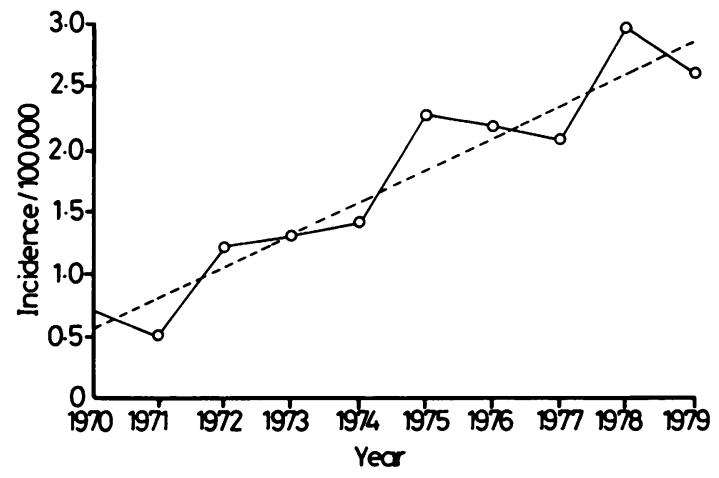

Fig 1 Age standardised incidence rates of melanoma in Rome, Italy, 1970-9. Annual incidence rate (solid line) and regression of incidence on year (broken line): $r=0.944$.

females is characterised by a rapid increase until the age of 40 followed by a leveling in middle age and later years, whereas in males the increase in incidence is progressive with age.

An improved diagnosis in older age groups of males may account for the observed differences; on the other hand, we may presume that a cohort effect is present for females, more recent birth cohorts having a higher risk of developing melanoma.

\section{ANATOMICAL SITE}

Increasing incidence is evident for all sites in both males and females (fig 3). However, patterns of occurrence remain almost unchanged in the decade examined. Among males the most common site is the trunk both in the first five-year period $(51 \%)$ and in the second $(52 \%)$, followed by the lower limb $(22 \%$

Number of new cases of malignant melanoma of the skin, age standardised incidence rates, and truncated incidence rates by year of diagnosis, Rome, Italy

\begin{tabular}{|c|c|c|c|c|c|c|c|c|}
\hline \multirow[b]{3}{*}{ Year } & \multicolumn{4}{|l|}{ Males } & \multicolumn{4}{|l|}{ Females } \\
\hline & \multirow[b]{2}{*}{ Population } & \multirow{2}{*}{$\begin{array}{l}\text { No of } \\
\text { cases }\end{array}$} & \multicolumn{2}{|c|}{ Incidence per 100000} & \multirow[b]{2}{*}{ Population } & \multirow{2}{*}{$\begin{array}{l}\text { No of } \\
\text { cases }\end{array}$} & \multicolumn{2}{|c|}{ Incidence per 100000} \\
\hline & & & All ages & Truncated ${ }^{*}$ & & & All ages & Truncated $^{*}$ \\
\hline 1970 & 1335075 & 14 & $1 \cdot 1$ & $1 \cdot 4$ & 1443797 & 5 & 0.3 & 0.5 \\
\hline 1971 & 1340211 & 5 & 0.2 & 0.7 & 1441782 & 11 & 0.7 & $1 \cdot 1$ \\
\hline 1972 & 1346224 & 14 & $1 \cdot 1$ & 1.4 & 1448944 & 20 & $1 \cdot 3$ & $1 \cdot 5$ \\
\hline 1973 & 1364784 & 15 & $1 \cdot 2$ & $1 \cdot 2$ & 1468319 & 21 & 1.4 & $2 \cdot 0$ \\
\hline 1974 & 1375534 & 21 & 1.6 & $2 \cdot 2$ & 1480775 & 18 & $1 \cdot 2$ & $1 \cdot 7$ \\
\hline 1975 & 1383808 & 35 & $2 \cdot 6$ & $3 \cdot 1$ & 1491030 & 31 & $2 \cdot 0$ & $2 \cdot 4$ \\
\hline 1976 & 1387699 & 30 & $2 \cdot 3$ & $2 \cdot 9$ & 1496297 & 31 & $2 \cdot 0$ & $2 \cdot 9$ \\
\hline 1977 & 1394080 & 26 & $2 \cdot 0$ & $1 \cdot 8$ & 1503739 & 34 & $2 \cdot 2$ & $3 \cdot 4$ \\
\hline 1978 & 1400903 & 43 & $3 \cdot 2$ & $2 \cdot 8$ & 1513739 & 44 & $2 \cdot 8$ & $3 \cdot 3$ \\
\hline 1979 & 1417519 & 34 & $2 \cdot 3$ & $2 \cdot 7$ & 1523847 & 48 & 2.9 & $4 \cdot 4$ \\
\hline
\end{tabular}

*Data restricted to age range $20-60$ years. 


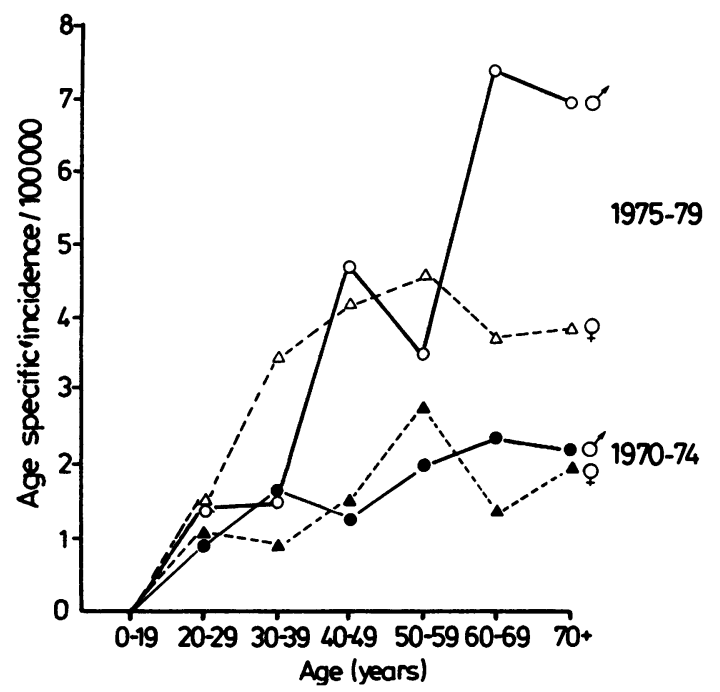

Fig 2 Average annual age specific incidence rates of melanoma by sex in Rome, Italy, in two successive five-year periods: $1970-4$ and 1975-9.

and $27 \%$ respectively); in females the most affected site is the lower limb, accounting for $75 \%$ of all cases in $1970-4$ and for $53 \%$ in $1975-9$, followed by the trunk ( $11 \%$ and $21 \%$ respectively). Therefore in both sexes about three-quarters of all cases occur on the trunk and lower limbs. In males $38 \%$ ( 22 cases) of
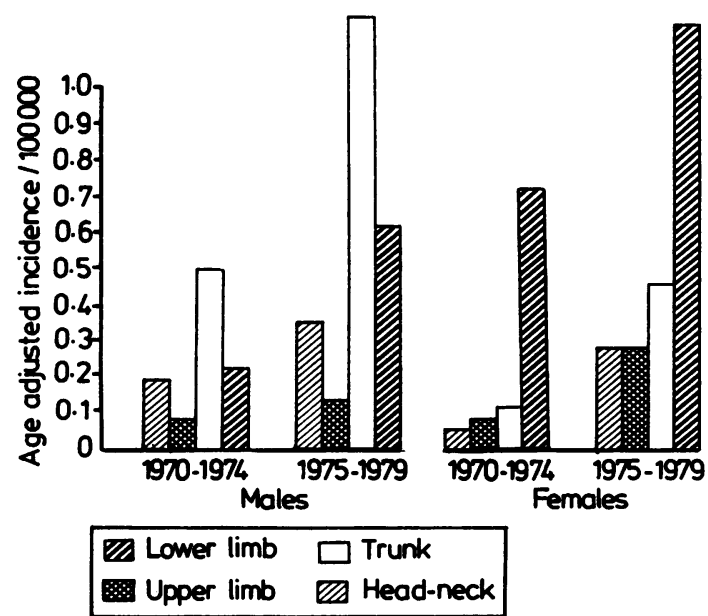

Fig 3 Age standardised incidence rates of melanoma by sex and anatomical site; average annual incidence rates are calculated for Rome, Italy, in two successive five-year periods: $1970-4$ and 1975-9. lower limb melanomas and $10 \%$ (15 cases) of female lower limb melanomas were located on the foot. Out of these, 13 cases have been found on the sole ( 9 in males and 4 in females). Only 8 cases (6 in females and 2 in males) have been found on the hand and palm.

\section{Conclusion}

This retrospective analysis shows that, in the study period, the incidence of melanoma was rapidly increasing. A possible underestimation of the incidence rate in more remote years, due to practical difficulties in collecting data, may account for the positive time trend; therefore it should be considered as artificial. However we must consider that the recording system did not change in the hospitals during the study period; it is also untenable, in our opinion, that an artificial increase in incidence was shown because of improved diagnostic evaluation, since the evaluation methods did not change during those years. Finally, it must be pointed out that the incidence in Rome at the beginning of the observation period was in the range of those reported in other Mediterranean and Latin countries. ${ }^{16}$ It must therefore be accepted that in Italy also this particular type of tumour is rapidly becoming more prevalent. It is likely that the same unknown aetiological factor(s) responsible for the rapid increase in incidence of malignant melanoma in other western countries are also active in Italy.

Latin countries generally have an incidence of malignant melanoma much lower than that of Anglo-Saxon and also other Caucasian populations. In the period 1968-72, the incidence in Spain (Zaragoza) was 0.3 per 100000 and in Malta 0.7 per 100000 while in the same years the incidence was 5.6 in Norway and 9.6 per 100000 in the population of English origin in New Zealand. ${ }^{16}{ }^{17}$ The lower incidence of malignant melanoma in Latin countries was attributed to the ethnic composition of the population which is presumably less prone to develop this type of tumour. This conclusion is also supported by the observation that the Latin minorities in the United States have a lower incidence of melanoma than Anglo-Saxons. ${ }^{16}$

The presented data, however, show that in a Mediterranean and Latin country such as Italy the incidence of malignant melanoma presents the same positive trend as that of other Caucasian populations, whether European or not. A similar trend has been recorded also among the people of Spanish origin of the New Mexico Cancer Register. ${ }^{18}$

These data do not permit any hypothesis concerning the nature of the aetiological factors involved. However in Italy the rapid rise in incidence 
during recent years could be related to the post war Italian economic development, which has followed the economic development of other western countries with a delay of some 10 years.

We thank the chiefs of the public and private hospitals in Rome and the Census Office of Rome for their cooperation in this study. We are also grateful to Dr Flaminia Portoghesi, Dr Caterina Vollono, and Mr Giullano Siepi for help with the collection of data.

\section{References}

'Jensen OM, Bolander AM. Trends in malignant melanoma of the skin. World Health Stats 1980; 33: 2-26.

${ }^{2}$ Holman CDJ, Mulroney CD, Armstrong BK. Epidemiology of pre invasive and invasive malignant melanoma in Western Australia. Int $J$ Cancer 1980; 25: 317-23.

${ }^{3}$ Anonymous. The aetiology of melanoma. Lancet 1981 ; i: 253-255.

${ }^{4}$ Beral V, Evans S, Shaw H, Milton G. Malignant melanoma and exposure to fluorescent lighting at work. Lancet 1982; 2: 290-3.

${ }^{5}$ Lee JAH, Storer BE. Further studies on skin melanomas apparently dependent on female sex hormones. Int $J$ Epidemiol 1982; 11: 127-31.

${ }^{6}$ Lee JAH. Melanoma and exposure to sunlight. Epid Rev 1982; 4: 110-36.

${ }^{7}$ Teppo L, Pakkanen M, Hakulinen T. Sunlight as a risk factor of malignant melanoma of the skin. Cancer 1978; 41: 2018-27.

${ }^{8}$ Kripke ML. Speculations on the role of ultraviolet radiation in the development of malignant melanoma. $J$ Natl Cancer Inst 1979; 63: 541-5.

${ }^{9}$ Magnus K. Incidence of malignant melanoma of the skin in the five Nordic Countries: significance of solar radiation. Int J Cancer 1977; 20: 477-85.

${ }^{10}$ Crombie IK. Variation of melanoma incidence with latitude in North America and Europe. Br J Cancer 1979; 40: 774-81.

${ }^{11}$ Elwood JM, Lee JAH, Walter SD, Mo T, Green AES. Relationship of melanoma and other skin cancer mortality to latitude and ultraviolet radiation in the United States and Canada. Int J Epidemiol 1974; 3: 325-32.

${ }^{12}$ Magnus K. Incidence of malignant melanoma of the skin in Norway, 1955-1970. Cancer 1973; 32: 1275-86.

${ }^{13}$ Swerdlow AJ. Incidence of malignant melanoma of the skin in England and Wales and its relationship to sunshine. Br Med J 1979; 2: 1324-7.

${ }^{14}$ Maggini M, Petrelli G. Malignant melanoma mortality in Italy: 1955-1978. Eur J Cancer Clin Onc 1984; 20: 1321-3.
${ }^{15}$ Crombie IK. Distribution of malignant melanoma on the body surface. $\mathrm{Br} J$ Cancer 1981; 43: 842-9.

${ }^{16}$ WHO-IARC. Cancer incidence in five continents. Waterhaus J, Muir C, Correa P, Powell J, Davis W, eds. Lyon 1976; III.

${ }^{17}$ Petrelli G, Maggini M, Vollono C, Taggi F, Morpurgo G. Incidenza del melanoma maligno della pelle in relazione a sesso, razza ed esposizione al sole. Rec Progr Med 1983; 74: 371-84.

${ }^{18}$ WHO-IARC. Cancer incidence in five countries. Waterhaus J, Muir C, Shanmugaretnam K, Possell J, eds. Lyons 1976; IV.

\section{Appendix}

Diagram of the survey conducted in Rome's private hospitals to ascertain the presence of cases of melanoma diagnosed in the period 1970-9. A questionnaire was mailed to 82 private hospitals inquiring about the number of cases of melanoma diagnosed in the period 1970-9. Second and third questionnaires were mailed to non-respondents. From among the respondents 19 cases of melanoma have been collected. We contacted a sample of private hospitals (both respondents and non-respondents) in order to estimate biases due to the procedure used. Fourteen private hospitals were investigated, representing 1303 hospital beds $(21 \%$ of the total private hospital beds) and 25 cases of melanoma were found, two of which (cases with the asterisk) had already been claimed by the private hospitals.

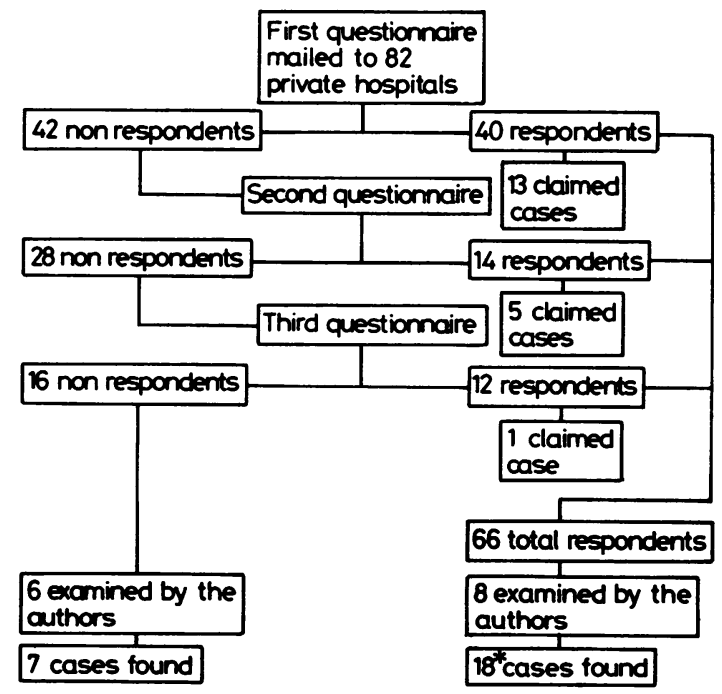

